JURNAL KACAPURI

JURNAL KEILMUAN TEKNIK SIPIL

Volume 4 Nomor 2 Edisi Desember 2021

\title{
PENGARUH PASAR SUBUH TERHADAP BIAYA TAMBAHAN PADA BIAYA OPERASIONAL KENDARAAN (BOK)
}

\author{
${ }^{1}$ Jose Imanuel, ${ }^{2}$ Supiyan dan Desi Riani ${ }^{3}$ \\ ${ }^{123}$ Program Studi Teknik Sipil, Fakultas Teknik, Universitas Palangka Raya \\ E-mail: joseimanuel15@gmail.com¹, supiyan@eng.upr.ac.id ${ }^{2}$, dan \\ desiriani@jts.upr.ac.id ${ }^{3} /$ HP.+62
}

\begin{abstract}
ABSTRAK
Kemacetan lalu lintas pada jalan perkotaan selalu menjadi masalah di berbagai kota di Indonesia. Secara umum ada beberapa faktor yang menyebabkan kemacetan yaitu terbatasnya fasilitas transportasi dan pembangunan jalan raya. Hal tersebut terlihat pada pasar subuh di Jalan Ahmad Yani, Kota Palangka Raya, Kalimantan Tengah, sering terjadi peningkatan kinerja jalan akibat adanya pasar subuh. Pada pasar subuh terdapat aktivitas jual beli yang menggunakan badan jalan dan fasilitas parkir yang menggunakan badan jalan. Sehingga pengguna jalan yang hanya melalui ruas jalan tersebut menerima dampak negatif yang berupa waktu tempuh yang lebih lama pada pengguna jalan tersebut.Tujuan penelitian adalah untuk mengetahui pengaruh parkir di badan jalan pada pasar subuh terhadap kinerja jalan akibat adanya aktivitas menggunakan badan jalan yang menyebabkan waktu tempuh kendaraan yang lebih lama. Pengumpulan data primer dilakukan dengan mencatat data arus lalu lintas, hambatan samping dan waktu tempuh. Sedangkan data sekunder di dapatkan dari Badan Pusat Statistik (BPS) kemudian analisis dilakukan dengan menggunakan metode HDM-VOC. Hasil dari survei yang dilakukan menunjukan bahwa dari hasil analisis dan perhitungan maka didapat external cost BOK rata-rata kendaraan ringan berdasarkan kecepatan sesungguhnya tanpa pasar subuh adalah Rp. 32,445/jam menjadi Rp. 34,415 /jam setelah adanya pasar subuh (terjadi peningkatan 2,12\%), sedangakan external cost berdasarkan kecepatan arus bebas pada kondisi tanpa pasar subuh adalah Rp. 32,445/jam menjadi Rp. 34,415/jam setelah adanya pasar subuh (terjadi peningkatan 6,07\%).
\end{abstract}

Kata Kunci: pasar subuh, HDM-VOC dan biaya tambahan

\section{ABSTRACT}

Traffic congestion on urban roads has always been a problem in various cities in Indonesia. In general, there are several factors that cause congestion, namely limited transportation facilities and road construction. This can be seen in the pasar subuh on Ahmad Yani streets, Palangka Raya City, Central Kalimantan, where road performance often increases due to the presence of the pasar subuh. At the pasar subuh, there are buying and selling activities that use the road body and parking facilities that use the road body. So that road users who only go through these roads receive a negative impact in the form of longer travel time on these road users. The purpose of this research is to see the effect of on-road parking at the pasar subuh on road performance due to activities using the road body which causes the vehicle travel time to take place longer. Primary data collection is carried out by recording data on traffic flow, side friction and travel time. 
JURNAL KACAPURI

JURNAL KEILMUAN TEKNIK SIPIL

Volume 4 Nomor 2 Edisi Desember 2021

Meanwhile, secondary data were obtained from the Badan Pusat Statistik (BPS) and then the analysis was carried out using the HDM-VOC method. The results of the survey conducted show that from the results of the analysis and calculations, it is found that the average VOC external cost of a vehicle based on the actual speed without the pasar subuh is Rp. 32,445 / hour to Rp. 34,415 / hour after the pasar subuh (an increase of 2.12\%), while the external cost based on the speed of free flow in conditions without the pasar subuh is Rp. 32,445 / hour to Rp. 34,415 / hour after pasar subuh (an increase of 6.07\%).

Key word: pasar subuh, HDM-VOC, external cost

\section{PENDAHULUAN}

Kemacetan adalah kondisi dimana arus lalu lintas yang lewat pad arusa jalan yang ditinjau melebihi kapasitas rencana jalan tersebut yang mengakibatkan kecepatan bebas ruas jalan tersebut mendekati $0 \mathrm{~km} / \mathrm{jam}$ yang menyebabkan terjadinya antrian (MKJI, 1997). Kemacetan menimbulkan kerugian yang sangat besar bagi pemakai jalan, terutama dalam hal pemborosan waktu (tundaan), pemborosan bahan bakar, pemborosan tenaga dan rendahnya kenyamanan berlalu lintas (Tamin, 2000). Salah satu ruas jalan di Kota Palangka Raya adalah Jalan Ahmad Yani yang merupakan jalan utama yang menghubungkan daerah pemukiman, perkantoran, pendidikan dan perdagangan. Penggunaan badan jalan akibat adanya aktivitas jual beli dari malam hingga subuh hari di Jalan Ahmad Yani yang tidak diimbangi dengan fasilitas parkir sehingga menggunakan badan jalan yang memberikan dampak kepada kemacetan lalu lintas. Pada parkir yang menggunakan badan jalan hal tersebut dapat menimbulkan terhambatnya arus lalu lintas dan berkurangnya tingkat pelayanan jalan, sehingga pengguna jalan menerima dampak negatif berupa waktu tempuh yang lebih lama yang pada akhirnya menyebabkan biaya tambahan (external cost) pada Biaya Operasional Kendaraan (BOK).

Tujuan dari penelitian ini adalah:

1) Mengetahui besarnya BOK kendaraan ringan saat dan sesudah adanya pasar subuh

2) Mengetahui besarnya external cost akibat adanya pasar subuh. 
JURNAL KACAPURI

JURNAL KEILMUAN TEKNIK SIPIL

Volume 4 Nomor 2 Edisi Desember 2021

\section{METODE PENELITIAN}

\section{Lokasi Penelitian dan Waktu Penelitian}

Penelitian dilakukan pada Jalan Ahmad Yani, Kecamatan Pahandut, Kota Palangka Raya, Kalimantan Tengah, dilakukan selama enam hari dimulai dari hari senin sampai hari sabtu pada jam puncak pukul 08.00-10.00 (pagi) WIB dan 20.00-22.00 (malam) WIB.

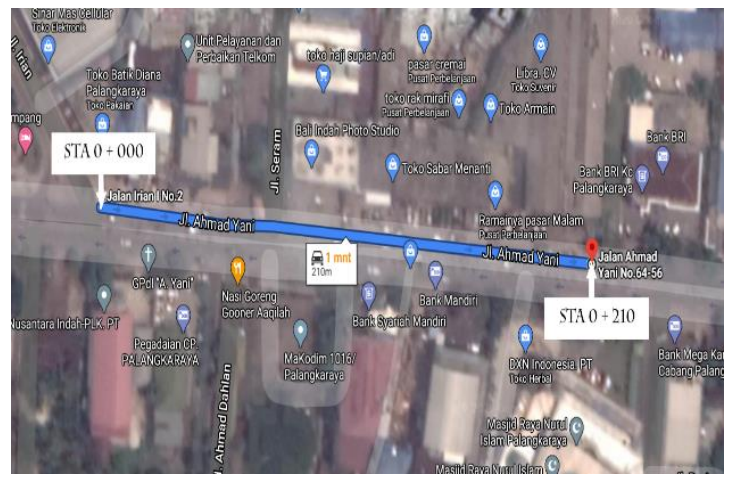

Gambar 1. Lokasi Penelitian

\section{Metode Pengumpulan Data}

\section{Geometrik Jalan}

Pada survei ini dilakukan pengukuran lebar jalur lalu lintas dan pengamatan kondisi jalan dan kondisi lingkungan sekitar.

\section{Data Primer}

Pada penelitian ini data primer di dapat dengan melaksanakan survei dengan mencatat data yang terdiri dari:

a. Survei arus lalu lintas

Pada survei ini dilakukan pengamatan dan pencatatan jumlah kendaraan yang melewati lokasi penelitian. Waktu survei dilakukan selama dua minggu, pada hari kamis sampai hari sabtu yaitu pukul 08.00-10.00 (pagi) dan 20.00-22.00 (malam).

\section{b. Survei Hambatan samping}

Pada survei ini dilakukan dengan cara mengamati dan mencatat jumlah kendaraan yang keluar dan masuk parkir, kendaraan berhenti, kendaraan lambat setiap 15 menit dalam interval waktu satu jam. 
JURNAL KACAPURI

c. Kecepatan waktu tempuh

Pada survei ini dilakukan pencatatan waktu tempuh saat melewati segmen yang sudah ditentukan dengan alat bantu tulis dan stopwatch.

\section{Metode Pengolahan Data}

Setelah data diperoleh dari survei selanjutnya dilakukan analisis yaitu menghitung volume, kapasitas jalan, kecepatan arus bebas dan derajat kejenuhan berdasarkan pedoman kapasitas jalan Indonesis (2014).

\section{HASIL \& PEMBAHASAN}

\section{Volume Arus Lalu Lintas}

Survei yang dilakukan pada jam-jam sibuk dengan pencatatan secara manual sehingga diperoleh volume lalu lintas.

Tabel 1. Volume Jam Puncak Di Pasar Subuh

\begin{tabular}{|c|c|c|c|c|c|c|}
\hline \multirow{2}{*}{ Waktu } & \multicolumn{5}{|c|}{ Jumlah Volume (Skr/jam) } \\
\cline { 2 - 7 } & Senin & Selasa & Rabu & Kamis & Jumat & Sabtu \\
\hline \hline $08.00-09.00$ & 679,7 & 768,1 & 818,8 & 708,6 & 807,4 & 660,0 \\
\hline $09.00-09.15$ & 738,1 & 797,6 & 921,8 & 723,8 & 832,9 & 682,9 \\
\hline $09.15-09.30$ & 732,4 & 814,0 & 1016,2 & 710,7 & 838,8 & 708,5 \\
\hline $09.30-09.45$ & 706,9 & 824,7 & 1028,2 & 701,7 & 849,6 & 688,9 \\
\hline $09.45-10.00$ & 661,9 & 834,5 & 1083,2 & 725,6 & 846,8 & 732,2 \\
\hline $21.09-21.30$ & 540,5 & 686,1 & 611,7 & 562,6 & 609,0 & 673,6 \\
\hline $20.00-21.00$ & 610,7 & 691,3 & 656,1 & 646,9 & 608,9 & 775,4 \\
\hline $21.00-21.15$ & 566,3 & 714,1 & 645,4 & 638,0 & 604,8 & 732,3 \\
\hline 21.45 & 468,7 & 640,2 & 552,2 & 506,4 & 635,0 & 594,1 \\
\hline & & & & & & \\
\hline
\end{tabular}


JURNAL KACAPURI

JURNAL KEILMUAN TEKNIK SIPIL

Volume 4 Nomor 2 Edisi Desember 2021

\begin{tabular}{|l|l|l|l|l|l|l|}
\hline $21.45-22.00$ & 427,8 & 598,7 & 454,9 & 347,3 & 650,2 & 534,1 \\
\hline
\end{tabular}

Sumber: Hasil analisis (2020)

\section{Hambatan Samping}

Data yang digunakan adalah jam tersibuk untuk kebutuhan analisis. Setelah dilakukan pengolahan dari data hambatan samping yang didapat.

Tabel 2. Hambatan samping di Pasar Subuh

\begin{tabular}{|c|c|c|c|c|c|c|}
\hline \multirow{2}{*}{ Waktu } & \multicolumn{6}{|c|}{ Jumlah Volume (Skr/jam) } \\
\hline & Senin & Selasa & Rabu & Kamis & Jumat & Sabtu \\
\hline $08.00-09.00$ & 53,9 & 41 & 59,8 & 40 & 26,2 & 43,7 \\
\hline $09.00-09.15$ & 57,2 & 40,6 & 78,9 & 40,5 & 29,9 & 50,2 \\
\hline $09.15-09.30$ & 63,3 & 36,7 & 84,6 & 40,1 & 33,9 & 44,3 \\
\hline $09.30-09.45$ & 72,4 & 33,8 & 82,7 & 43,3 & 40,3 & 41,6 \\
\hline $09.45-10.00$ & 64,8 & 30,6 & 81,5 & 48 & 49,2 & 44,1 \\
\hline $20.00-21.00$ & 124,4 & 62,1 & 147,3 & 134,4 & 136,2 & 165,2 \\
\hline $21.00-21.15$ & 117,8 & 53,6 & 149,4 & 151,7 & 121,1 & 162 \\
\hline $21.15-21.30$ & 110,7 & 50,2 & 147,8 & 153,6 & 129,3 & 158,9 \\
\hline $21.30-21.45$ & 116,5 & 50,5 & 137,6 & 147,7 & 137,7 & 144,8 \\
\hline $21.45-22.00$ & 110,5 & 47,3 & 141,7 & 160,6 & 146,8 & 146,2 \\
\hline
\end{tabular}

Sumber: Hasil analisis (2020)

\section{Kecepatan Arus Bebas Kendaraan}

Jalan Ahmad Yani merupakan tipe jalan 4 jalur 2 arah terbagi 4/2T, dengan lebar jalur $7 \mathrm{~m}$. Berikut adalah perhitungan kecepatan arus bebas:

$\mathrm{VB}=(57+4) \times 1,00 \times 0,93=56,73 \mathrm{~km} / \mathrm{jam}$

Berdasarkan hasil perhitungan diatas dapat dilihat bahwa kecepatan arus bebas kendaraan di Jalan Ahmad Yani adalah 56,73 km/jam. 
JURNAL KACAPURI

JURNAL KEILMUAN TEKNIK SIPIL

Volume 4 Nomor 2 Edisi Desember 2021

Tabel 3. Waktu dan Kecepatan tempuh saat pasar subuh

\begin{tabular}{|c|c|c|c|c|c|c|}
\hline \multirow{2}{*}{ Waktu } & \multicolumn{5}{|c|}{ Jumlah Volume (Skrjam) } \\
\cline { 2 - 7 } & Senin & Selasa & Rabu & Kamis & Jumat & Sabtu \\
\hline \hline $08.00-09.00$ & 28,1 & 27,6 & 28,0 & 28,2 & 27,6 & 27,8 \\
\hline $09.00-09.15$ & 28,0 & 27,8 & 28,1 & 28,1 & 27,8 & 27,9 \\
\hline $09.15-09.30$ & 28,1 & 27,9 & 28,2 & 28,3 & 28,1 & 27,9 \\
\hline $09.30-09.45$ & 28,5 & 28,3 & 28,4 & 28,6 & 28,5 & 28,0 \\
\hline $09.45-10.00$ & 29,1 & 28,7 & 28,5 & 28,8 & 28,9 & 28,3 \\
\hline & & & 38,9 & 32,0 & 32,0 \\
\hline $20.00-21.00$ & 40,2 & 37,2 & 36,4 & 30,0 & 30,0 & 32,0 \\
\hline $21.00-21.15$ & 39,3 & 37,9 & 37,1 & 29,9 & 30,0 & 32,1 \\
\hline $21.15-21.30$ & 38,1 & 38,0 & 37,2 & 30,1 & 30,0 & 32,1 \\
\hline $21.30-21.45$ & 37,2 & 38,3 & 38,0 & 30,4 & 30,1 & 32,3 \\
\hline $21.45-22.00$ & 38,1 & 38,7 & 38,1 & 30,8 & 30,1 & 32,4 \\
\hline
\end{tabular}

Sumber: Hasil analisis (2020)

\section{Analisis Biaya Operasional Kendaraan (BOK)}

Analisis diperlukan untuk mengetahui besar biaya yang dikeluarkan oleh pengguna kendaraan sebelum dan sesudah adanya pasar subuh, sehingga diketahui external cost yang terjadi:

Tabel 4. Rekapitulasi Arus Total

\begin{tabular}{|c|c|}
\hline Hari & Kendaraan Ringan \\
\hline \hline Senin & 268 \\
\hline Selasa & 384 \\
\hline Rabu & 331 \\
\hline Kamis & 370 \\
\hline Jumat & 329 \\
\hline
\end{tabular}


JURNAL KACAPURI

JURNAL KEILMUAN TEKNIK SIPIL

Volume 4 Nomor 2 Edisi Desember 2021

\begin{tabular}{|c|c|}
\hline Sabtu & 401 \\
\hline
\end{tabular}

Sumber: Hasil analisis (2020)

Tabel 5. BOK kendaraan ringan saat pasar subuh

\begin{tabular}{|c|c|}
\hline Hari & Kendaraan Ringan \\
\hline \hline Senin & Rp. 53,140 \\
\hline Selasa & Rp. 76,240 \\
\hline Rabu & Rp. 65,654 \\
\hline Kamis & Rp. 73,323 \\
\hline Jumat & Rp. 65,005 \\
\hline Sabtu & Rp. 79,616 \\
\hline Jumlah & Rp. 412,980 \\
\hline Rata-rata & Rp. 34,415 \\
\hline
\end{tabular}

Sumber: Hasil analisis (2020)

Tabel 6. BOK kendaraan ringan tanpa pasar subuh

(berdasarkan kecepatan arus bebas dan kecepatan aktual)

\begin{tabular}{|c|c|c|}
\hline \multirow{2}{*}{ Hari } & \multicolumn{2}{|c|}{ Kendaraan Ringan } \\
\cline { 2 - 3 } & Kecepatan arus bebas & Kecepatan aktual \\
\hline \hline Senin & Rp. $50,093.26$ & Rp. $51,338.98$ \\
\hline Selasa & Rp. $71,775.41$ & Rp. $73,661.04$ \\
\hline Rabu & Rp. $61,868.91$ & Rp. $63,580.95$ \\
\hline Kamis & Rp. $69,158.60$ & Rp. $72,825.03$ \\
\hline Jumat & Rp. $61,495.08$ & Rp. $64,722.07$ \\
\hline Sabtu & Rp. $74,952.97$ & Rp. $78,307.19$ \\
\hline Jumlah & Rp. $389,344.22$ & Rp. $404,435.26$ \\
\hline
\end{tabular}


JURNAL KACAPURI

JURNAL KEILMUAN TEKNIK SIPIL

Volume 4 Nomor 2 Edisi Desember 2021

\begin{tabular}{|c|c|c|}
\hline Rata-rata & Rp. $32,445.35$ & Rp. $33,702.94$ \\
\hline
\end{tabular}

Sumber: Hasil analisis (2020)

Langkah selanjutnya adalah menentukan external cost dengan menghitung selisih antara BOK pada kondisi pasar subuh pada dan tanpa pasar subuh pada kecepatan sesungguhnya dan hasil perhitungan BOK dapat dilihat pada tabel 7.

Tabel 7. External Cost BOK kendaraan ringan saat pasar subuh (berdasarkan kecepatan aktual dan kecepatan arus bebas)

\begin{tabular}{|c|c|c|}
\hline \multirow{2}{*}{ Hari } & \multicolumn{2}{|c|}{ Kendaraan Ringan } \\
\hline & Kecepatan arus bebas & Kecepatan aktual \\
\hline Senin & Rp. $3,046.89$ & Rp. $1,801.17$ \\
\hline Selasa & Rp. $4,464.88$ & Rp. 2,579.24 \\
\hline Rabu & Rp. $3,785.44$ & Rp.2,073.40 \\
\hline Kamis & Rp. 4,165.28 & Rp. 498.86 \\
\hline Jumat & Rp. $3,510.45$ & Rp. 283.46 \\
\hline Sabtu & Rp. 4,663.24 & Rp. $1,309.02$ \\
\hline Jumlah & Rp. $23,636.18$ & Rp. 8,545.14 \\
\hline Rata-rata & Rp.1,969.68 & Rp. 712.10 \\
\hline
\end{tabular}

Sumber: Hasil analisis (2020) 
JURNAL KACAPURI

JURNAL KEILMUAN TEKNIK SIPIL

Volume 4 Nomor 2 Edisi Desember 2021

\section{PENUTUP}

\section{Kesimpulan}

1. BOK rata-rata kendaraan ringan pada jam puncak berdasarkan kecepatan sesungguhnya pada kondisi tanpa pasar subuh adalah Rp. 33,702 /jam menjadi Rp. 34,415 setelah adanya pasar subuh (terjadi peningkat 2,12\%).

2. BOK rata-rata kendaraan ringan pada jam puncak berdasarkan kecepatan arus bebas PKJI 2014 pada kondisi tanpa pasar subuh adalah Rp. 32,445 menjadi Rp. 34,415 setelah adanya pasar subuh (terjadi peningkat 6,07\%).

3. External cost akibat adanya kegiatan pasar pasar subuh dengan metode HDM-VOC berdasarkan kecepatan sesungguhnya adalah Rp. 712,10/jam dan berdasarkan kecepatan bebas adalah Rp. $1.969,68 /$ jam.

\section{Saran}

1. Dari hasil analisis yang didapatkan penyebab terjadinya penurunan kecepatan yaitu hambatan samping, perlu diadakan pemasangan rambu-rambu arus lalu lintas atau marka jalan, antara lain rambu dilarang berhenti atau zebra cross.

2. Disarankan kepada para pedagang agar lebih tertib dalam mengelola barang dagangannya dan bagi pengendara untuk lebih taat dalam berlalu lintas, sehingga dapat mengurangi kemacetan. 


\section{DAFTAR PUSTAKA}

1. Anonim. Direktorat Jendral Bina Marga. 2014. Pedoman Kapasitas Jalan Indonesia (PKJI). Jakarta.

2. Anonim. World Bank. 1993. Highway Design and Maintenance Standard Vehicle Operating Cost.

3. Adi, Ari Sasmoko. 2019. Biaya Operasional Kendaraan Akibat Adanya Hambatan Samping Di Badan Jalan. Peneliti Muda pada Balitbang Kalimantan Timur. Samarinda.

4. Arafat, M. Yasir. 2014. Analisis Biaya Operasional Kendaraan Dan Waktu Perjalanan. Fakultas Teknik Universitas Syiah Kuala. Aceh.

5. Azmi, Ulul. 2017. Model Biaya Operasional Kendaraan Sepeda Motor Menggunakan Analisis Regresi Linier Berganda. Fakultas Teknik Universitas Teuku Umar. Aceh.

6. Bolla, Margareth E. 2017. Biaya Kemacetan Ruas Jalan Kota Kupangg Ditinjau Dari Segi Biaya Operasional Kendaraan. Fakultas Sains dan Teknik Univesitas Nusa Cendana. Kupang.

7. Meirisky, Andy. 2018. Analisis Kebutuhan Lahan Parkir Di Fakultas Teknik Universitas Palangka Raya. Fakultas Teknik Program Studi Teknik Sipil Universitas Palangka Raya. Palangka Raya

8. Mubin, Chairul. 2011. Analisis Biaya Operasional Kendaraan Jenis Sepeda Motor. Fakultas Teknik Program Studi Teknik Sipil Universitas Indonesia. Depok.

9. Permana, Satria. 2016. Pengaruh Hambatan Samping Terhadap Kinerja Jalan, Biaya Operasional Kendaraan Dan Biaya kemacetan Jalan Gatot Subroto Kota Malang. Fakultas Teknik Program Studi Teknik Sipil Universitas Brawijaya. Malang.

10. Tamin, O.Z. 2000. Perencanaan dan Pemodelan Transportasi. Penerbit Institut Teknologi Bandung. Bandung. 